\title{
Simulation of Grid Connected THIPWM-Three-Phase Inverter Using SIMULINK
}

\author{
M.A.A. Younis ${ }^{1}$ \\ ${ }^{1}$ Dept. of Electrical Power Engineering, UNITEN, \\ Selangor, Malaysia \\ E-Mail:amahmoud@uniten.edu.my
}

\begin{abstract}
Three phase DC-AC inverters used to convert the regulated DC power to AC power suitable for grid connection. Third harmonic injection PWM (THIPWM) was employed to reduce the total harmonic distortion (THD) and for maximum use of the voltage source. the accurate generation of THIPWM minimize the THD and make the inverter suitable for grid connection, by synchronizing the inverter voltage with the grid voltage. The application of THIPWM to inverter increases efficiency of the inverter. Simulation results validate the developed model and the proposed system.
\end{abstract}

Keywords: Three-phase inverter, Third harmonic injection PWM, Grid connection.

\section{INTRODUCTION}

The demand for electricity for commercial, industrial and domestic loads in rural, semi-urban and urban areas has grown tremendously over the years. The increase of energy consumption increases the demand on renewable energy, and more grid-connected systems are used. However, when these systems are used in large scale, the harmonics pollution of its output current can not be ignored [1]. According to related standards, the total harmonics distortion of output gridconnected current of inverter must be less than 5\%, and each harmonic distortion must be less than 3\% [2]. Most distributed resources are connected to the grid via an isolating transformer. Power supply utilities require the elimination of possible zero sequence or DC components in the generated voltages and for the increased protection. This fact can be used as an advantage since the transformer can form part of filter impedance and may, therefore, reduce the undesired harmonic content of the output current. During the past decade, digital control in power electronics has been intensively used [3].

The trend toward modular construction of power electronic systems can increase power capacity and also improve system efficiency [3]. Power quality of grid connected inverter is an important factor especially in high power applications. The power quality is determined by the voltage quality, when the voltage is a controlled variable. If there is connection to an existing grid, then the voltage cannot be controlled. The power quality is then defined by the current quality [4].

\section{GRID CONNECTED SYSTEM}

To avoid introducing extra distortions to the grid power, the generated currents from these inverters should have low

\author{
N. A. Rahim ${ }^{2}$ and S. Mekhilef ${ }^{3}$ \\ ${ }^{2,3}$ Dept. of Electrical Engineering, University of Malaya, \\ Kuala Lumpur, Malaysia.
}

harmonics and a high power factor. Furthermore, when the output currents are in phase with the grid voltages, the maximum real output power is achieved by minimizing the reactive component [5]. The grid-connected inverters are desired to have high power-quality, high efficiency, high reliability, low cost, and simple circuitry. With development and utilization of an unstable DC voltage source recently, grid connected inverters are widely used as essential power electronic devices for a grid-connected system. With PWM control technologies, the $\mathrm{AC}$ side of the grid-connected inverter has the abilities of controllable power factor, sinusoidal output currents and bi-directional power transfer [6] [7]. The power rating of grid-connected inverter is usually high; therefore switching frequency of the inverter is usually low.

The block diagram of the grid-connected system is shown in Figure 1. Six-step modulation uses a sequence of six switch patterns for three-phase full-bridge inverter, to generate a full cycle of three-phase voltages. The inverter output voltage has the same frequency and amplitude with those of the grid voltage. The synchronization of the inverter output voltage with the grid voltage must be done in such a way that the two voltages are in phase.

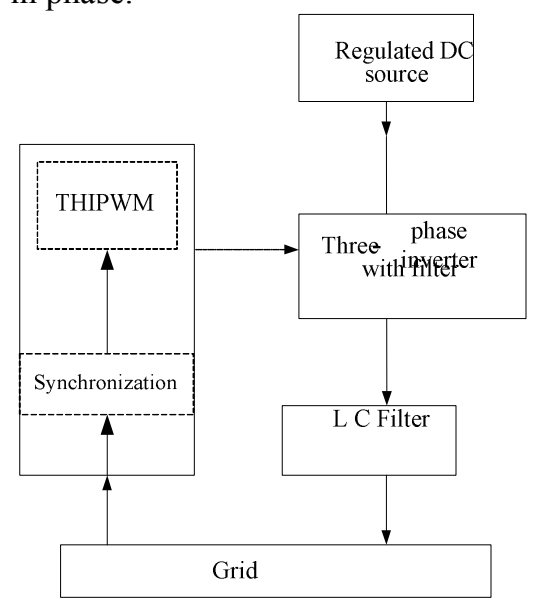

Figure 1: Block diagram of the grid-connected system

The proposed system is designed to supply the three-phase load and the grid as well. Two types of load selected for the system testing, the first load was resistive load with $1 \mathrm{~kW}$ rating and the second is RL load with a rating of $1 \mathrm{kVA}$. Figure 2 shows simplified connection arrangement for the 
system single line diagram. The electromagnetic switch $\mathrm{S}_{1}$ connects the power to three phase load from the grid and the inverter. The electromagnetic switch $\mathrm{S}_{2}$ connects the inverter to the grid.

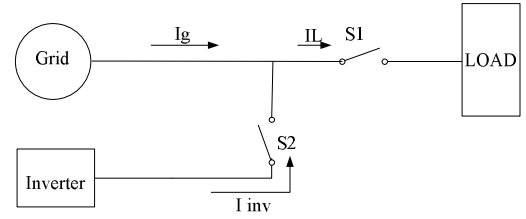

Figure 2: System connection to the grid

\section{THREE PHASE INVERTER}

A standard three-phase inverter is shown in Figure 3 consisting of six controlled switches such as IGBT. In this converter, the line currents can be shaped to be sinusoidal at a unity power factor, as well as the output ac voltage can be regulated at a desired value. The inverter is connected to the grid through three LC filters. THIPWM employed to make full use of the input voltage with minimum harmonic distortion in the output voltage and current.

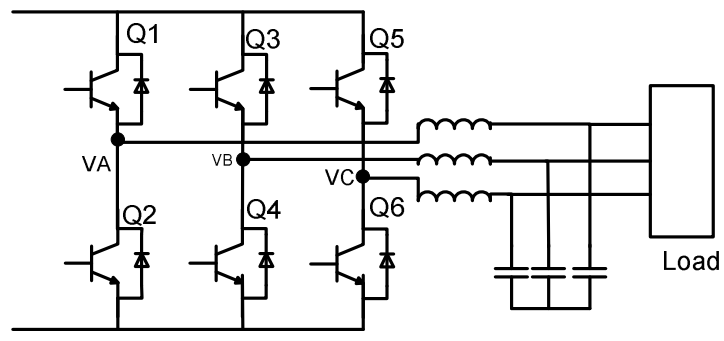

Figure 3: Three-phase inverter

\section{Third Harmonic Injection PWM}

Third Harmonic Injection PWM is preferred in three-phase application, because third-harmonic component will not be introduced in three-phase systems. THIPWM is better in utilization of DC source. Among the modulation techniques used for three phase inverter, space vector modulation (SVM) extends the linear modulation range $15 \%$ more compared with pure sine-wave (SPWM). This advantage can be achieved through injection of triplen harmonics to the sine-wave modulating signal, which result in third harmonic injection modulation or multiple harmonic injection modulation. As such, SVM and THIPWM offer the same advantages as compared with SPWM schemes. However, simple and direct implementation of THIPWM gives it advantage over the SVM, for the reason that no need to track the operating sector or add a state machine for switch sequencing of THIPWM. In terms of harmonic distortion, high switching frequency THIPWM makes it appropriate for harmonic distortion elimination [8].

The modulating signal is generated by injecting the third harmonic component to the $50 \mathrm{~Hz}$ fundamental component as given in equation 1.

$V_{r a}=1.15 \sin \omega t+0.19 \sin 3 \omega t$

$$
\begin{aligned}
& V_{r b}=1.15 \sin \left(\omega t-\frac{2}{3} \pi\right)+0.19 \sin 3 \omega t \\
& V_{r c}=1.15 \sin \left(\omega t-\frac{4}{3} \pi\right)+0.19 \sin 3 \omega t
\end{aligned}
$$

Using the modulator given in equation 1 will maintain the peak voltage equal to the dc voltage. Look-up table used to save the data of equation 1 which ultimately obtain threephase THIPWM for the three-phase inverter. The carrier signal shown in Figure4 used to be compared with the modulated signals to result in THIPWM. The THIPWM was modelled as shown in Figure 5. Figure 6 shows the THIPWM generation.

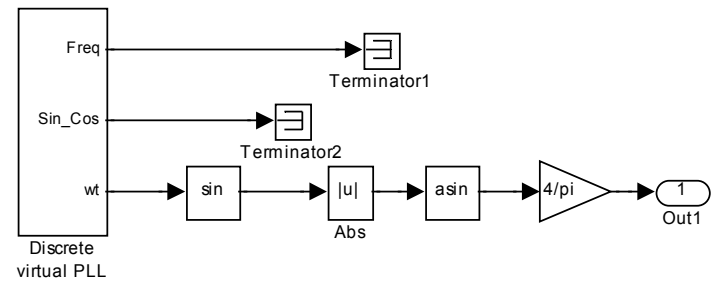

Figure 4: Carrier signal generation model

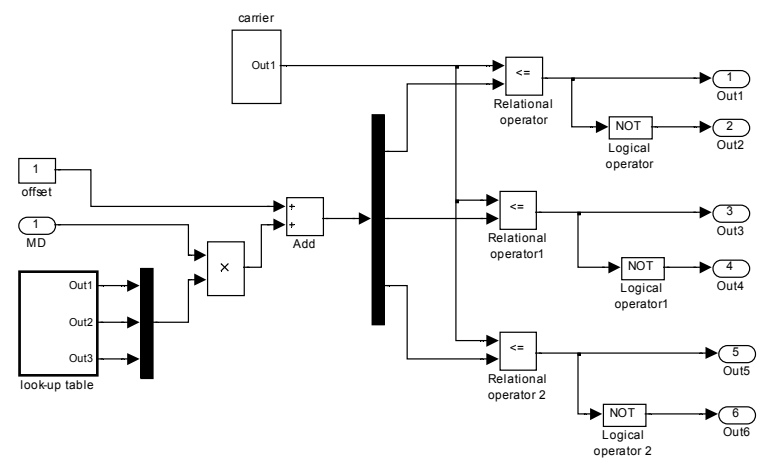

Figure 5: THIPWM generation model

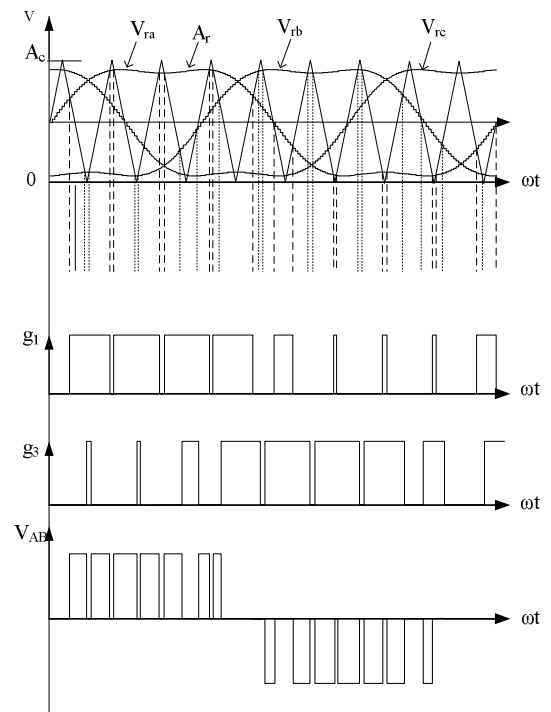

Figure 6: Generation of THIPWM 


\section{Grid connection System Model}

Figure 7 shows the overall system diagram which consists of three-phase inverter, and three phase generator acting as the grid. In this configuration the inverter model directly supplies three phase load. The three-phase generator supplies the same load through three-phase circuit breaker (CB). When the inverter voltage reaches the steady-state the circuit breaker will close to connect both the inverter and the generator to the same load.

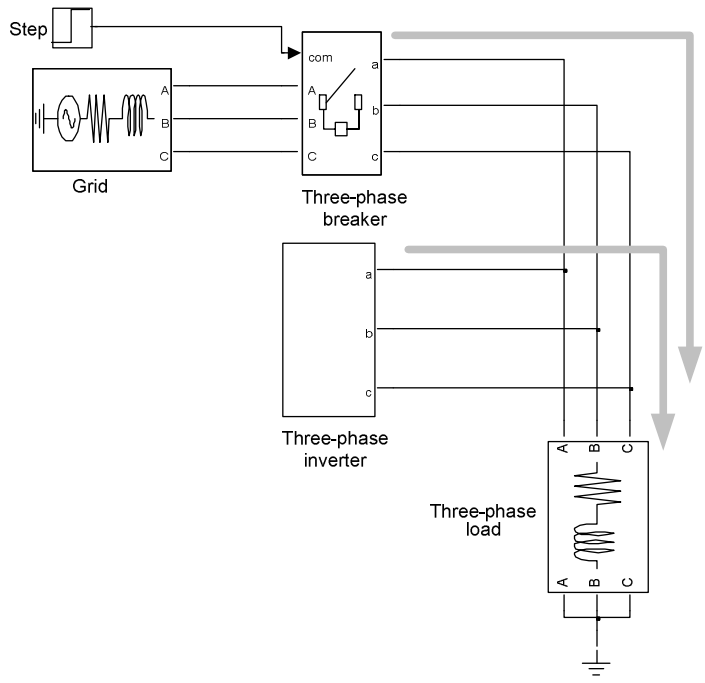

Figure 7: The inverter connection to the grid.

\section{Simulation Result}

The SIMULINK simulation result is given to verify the operation on the THIPWM three-phase inverter. The inverter was supplied by $200 \mathrm{~V}$ DC from the DC-DC converter. The result obtained is shown below. Figure 8(a) shows the THIPWM generation, where the third harmonic, acting as a reference, is compared with the triangular waveform THIPWM which is shown in Figure 8(b).
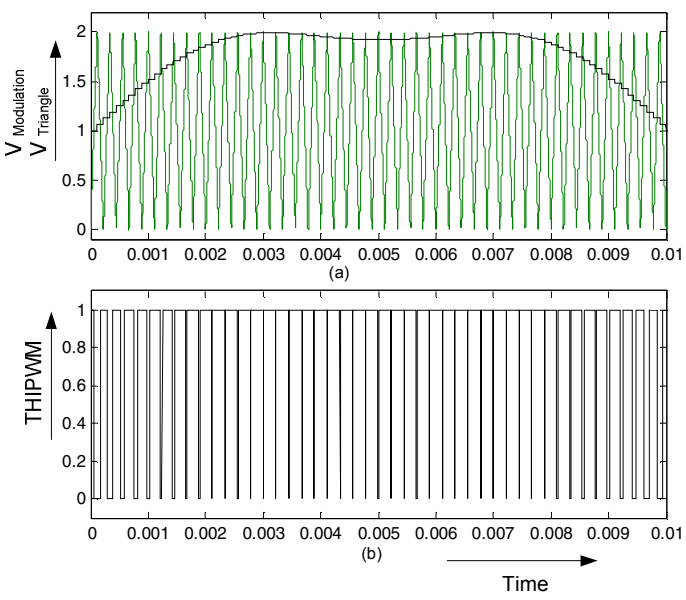

Figure 8: Half cycle THIPWM generation (from top to bottom) (a) Third harmonic injection modulator compared with the triangular waveform, (b) Resulting THIPWM
The three-phase inverter results obtained with the parameters shown in table 1.

Table 1: three-phase inverter parameters

\begin{tabular}{|c|c|c|}
\hline Parameter & Value & Unit \\
\hline DC Input voltage & 200 & $\mathrm{~V}$ \\
\hline L filter & 5 & $\mathrm{mH}$ \\
\hline C filter & 10 & $\mu \mathrm{F}$ \\
\hline Switching frequency & 4.5 & $\mathrm{kHz}$ \\
\hline $\mathrm{R} 1\left(\mathrm{R}_{11}, \mathrm{R}_{12}, \mathrm{R}_{13}\right)$ & 0.5 & $\Omega$ \\
\hline $\mathrm{R} 2\left(\mathrm{R}_{21}, \mathrm{R}_{22}, \mathrm{R}_{23}\right)$ & 0.6 & $\Omega$ \\
\hline
\end{tabular}

Figure 9shows the line voltage $\mathrm{V}_{\mathrm{ab}}$ with its harmonic spectrum before connecting the low-pass filter. Additionally, the line voltage $\mathrm{V}_{\mathrm{ab}}$ and the phase voltage $\mathrm{V}_{\mathrm{an}}$ are shown in Figure 10 . After using a low pass filter the phase current and the line voltage with their harmonic spectrum are shown in Figure 11 and Figure 12, respectively. It has been found that the current THD is $0.75 \%$ and the voltage THD is $1.57 \%$. Figure 13 and Figure 14 show the three-phase current and the three-phase line voltage respectively. The phase current, the phase voltage and phase angle could be obtained from Figure 15 which shows minimum phase shift.

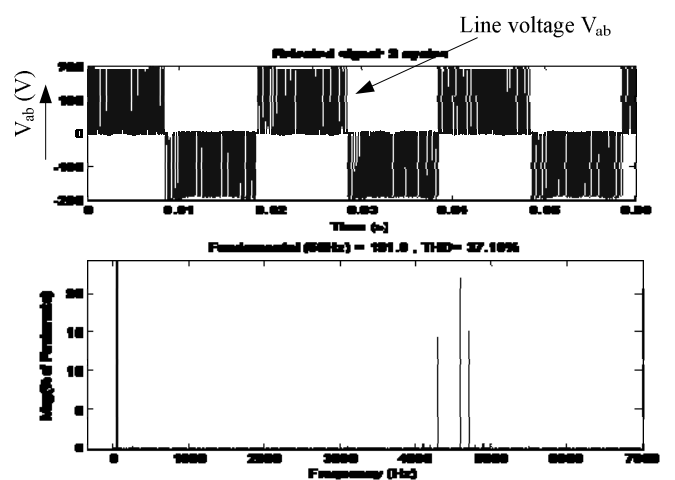

Figure 9: line voltage $\mathrm{V}_{\mathrm{AB}}$ with its harmonic spectrum

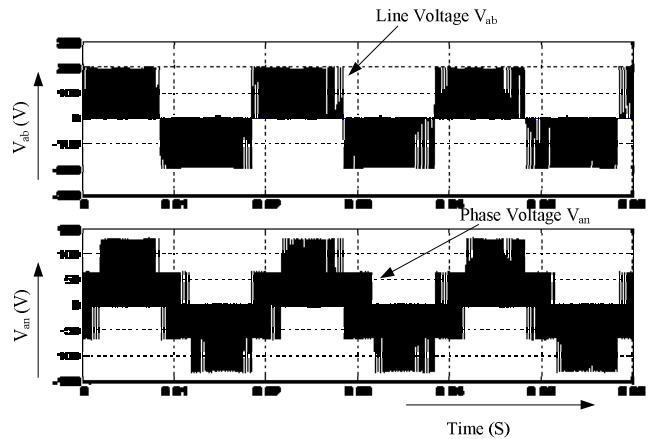

Figure 10: The line voltage $\mathrm{V}_{\mathrm{ab}}$ and the phase voltage $\mathrm{V}_{\mathrm{an}}$ without LC filter 


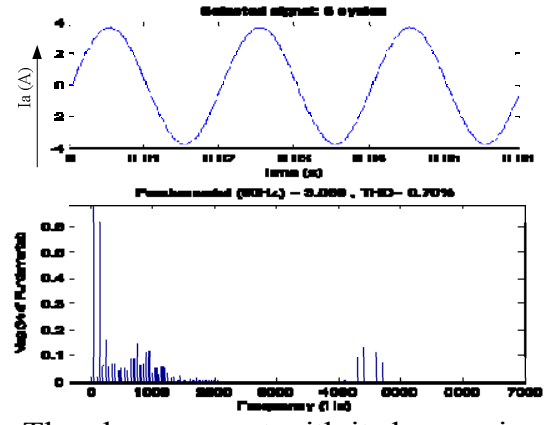

Figure 11: The phase current with its harmonic spectrum, $\mathrm{THD}=0.75 \%$

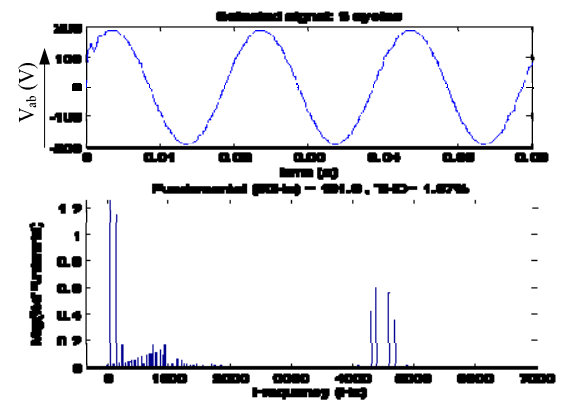

Figure 12: The line voltage $\mathrm{V}_{\mathrm{AB}}$ with Its harmonic spectrum $\mathrm{THD}=1.57 \%$

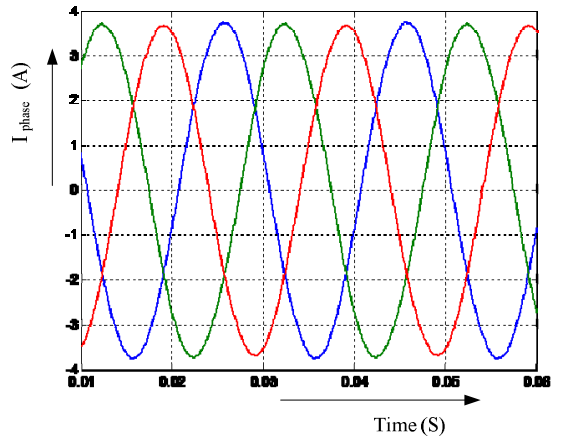

Figure 13: Thee-phase phase currents with filter included

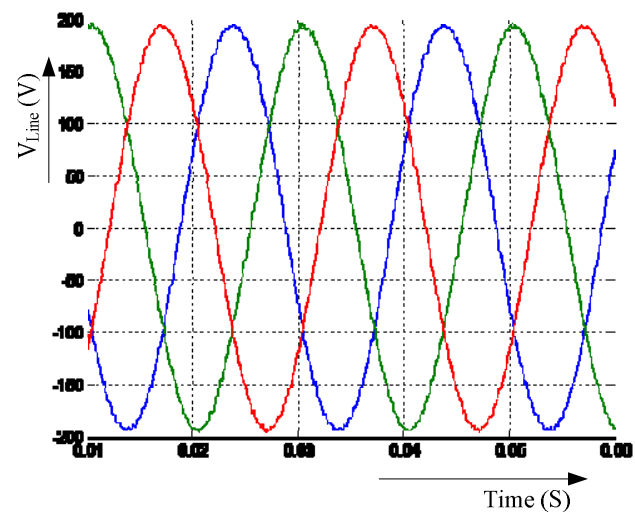

Figure 14: Thee-phase line voltages with filter included

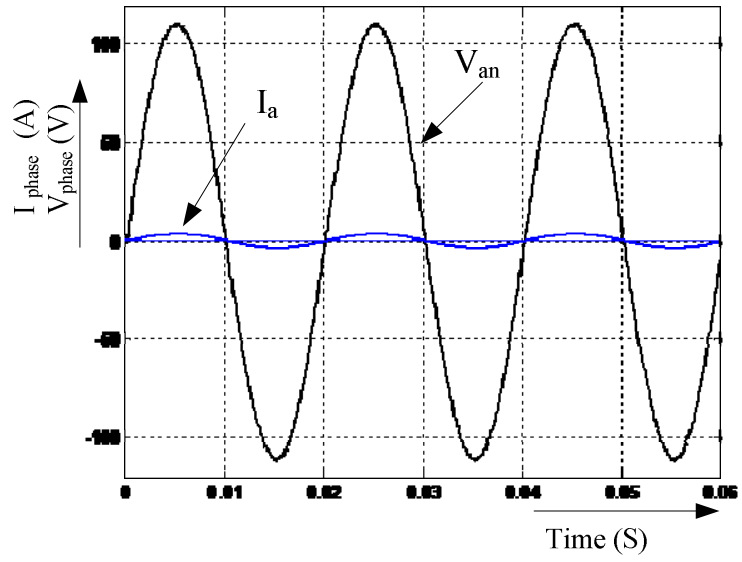

Figure 15: The phase current $I_{a}$ and the phase voltage $V_{a n}$

In the grid connection test, the inverter is connected to the three-phase load. The same load is also supplied by threephase generator acting as grid, through three-phase circuit breaker $(\mathrm{CB})$. The $\mathrm{CB}$ is closed to connect the generator power to the load after 2 cycle of the inverter operation. By the operation of the $\mathrm{CB}$ both the generator and the proposed system are supplying power to the same load. Figure 16 shows the step signal, inverter and grid voltage, and the inverter output current. The inverter current has been reduced to approximately $50 \%$ after the connection to the grid. This shows that both the inverter and the grid are sharing equal current to the load.

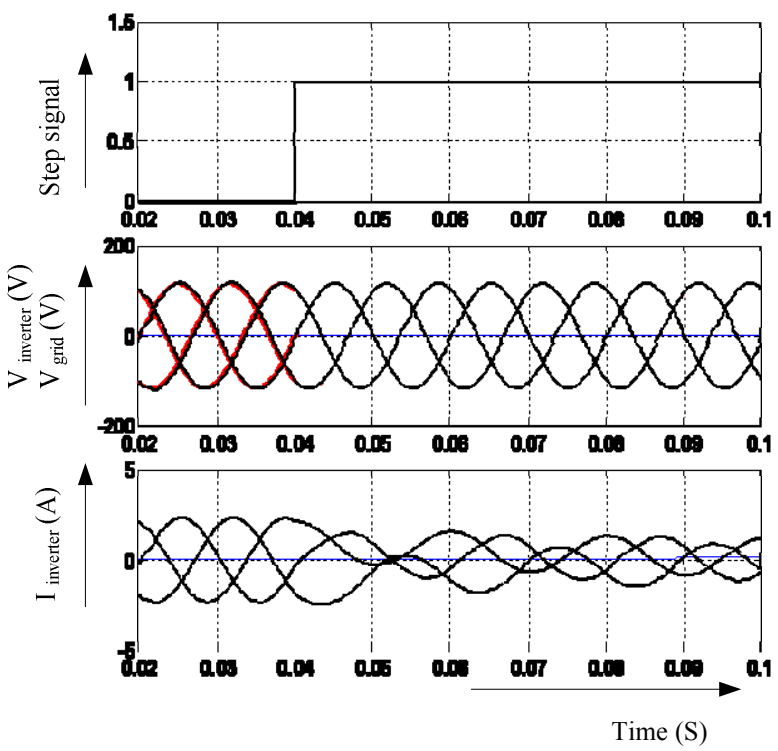

Figure 16: Grid connection (from top to bottom) CB control step signal, $\mathrm{V}_{\text {inverter }}$ and $\mathrm{V}_{\text {grid }}$, and $\mathrm{I}_{\text {inverter }}$

\section{Conclusion}

VIII. Third harmonic injection pulse width modulation (THIPWM) pattern with adjustable modulation index and displacement angle has been developed. High 
switching frequency is used to reduce the size of the LC filter and the complexity of the inverter. The inverter performance was satisfactory in terms of current and voltage total harmonic distortion (THD) injected to the grid. From the simulation result, it shows that the THD of the inverter output current and voltage injected to the grid are within the stipulated limits laid down by the international standard

\section{References}

[1] Z. Shicheng, W. Peizhen, G. Lusheng, 'Study on Improving Output Current Waveform of Photovoltaic Grid-Connected System' 1ST IEEE Industrial Electronics and Applications, 2006, pp. $1-5$

[2] IEEE Recommended Practices and Requirements for Harmonic Control in Electrical Power Systems, IEEE Std. 519-1992, 1993. - The conclusion is indented and is preceded by VIII. It should be in the same style as the other sections.

[3] Prodanovic M., Green T.C., 'Control and filter design of three-phase inverters for high power quality grid connection' IEEE Transactions on Power Electronics, vol.18, Issue 1, Part 2, Jan. 2003 pp. 373 - 380.

[4] M. H. Bollen, Understanding Power Quality Problems. Piscataway, NJ: IEEE Press, 2000.

[5] Chongming Qiao, Smedley K.M., 'Three-phase gridconnected inverters interface for alternative energy sources with unified constant-frequency integration control' Industry Applications Conference, 2001. ThirtySixth IAS Annual Meeting. Conference Record of the 2001 IEEE Volume 4, 30 Sept.-4 Oct. 2001 vol.4 pp.2675 $-2682$

[6] I. J. Pitel, S. N. Talukdar, and P. Wood, 'Characterization of Programmed-Waveform Pulse-Width Modulation,' IEEE Transactions on Industry Applications, Vol. IA-16, Sept./Oct. 1980, pp. 707-715.

[7] Fainan A., Magueed, and Jan Svensson, 'Control of VSC connected to the grid through LCL filter to achieve balanced currents,' IEEE Industry Applications Society Annual Meeting 2005, vol. 2, pp. 572-578

[8] Kwasinski A., Krein P.T., Chapman P.L., 'Time domain comparison of pulse-width modulation schemes' IEEE Power Electronics Letters, vol. 1, Issue 3, Sept. 2003, pp.64-68. 